\title{
TECENDO UMA IDEIA CRÍTICA SOBRE A LUSOFONIA EM TIMOR- LESTE: ENTRE A POLÍTICA LINGUÍSTICA DE FATO E A DE DIREITO
}

\author{
WEAVING A CRITICAL IDEA ON LUSOPHONY IN TIMOR-LESTE: \\ BETWEEN LANGUAGE POLICIES AND LANGUAGE POLICIES DE FACTO
}

Alexandre Cohn da Silveira Doutorando em Linguística pela Universidade Federal de Santa Catarina Membro do Políticas Linguísticas Críticas ${ }^{1}$ bestxandy@gmail.com

Christiane da Silva Dias Doutoranda em Linguística pela Universidade Federal de Santa Catarina Professora de PLA/PLE e da rede estadual de Ensino de Santa Catarina christianedias@hotmail.com

Resumo: As turbulências históricas e políticas vivenciadas em Timor-Leste motivaram uma decisão política estatal pela co-oficialização da língua portuguesa no pequeno país multilíngue asiático. Esta decisão, no entanto, embora pretenda caracterizar o país como lusófono "de direito", configura a criação de uma "comunidade imaginada" lusófona (ANDERSON, 2008) uma vez que as políticas linguísticas “de fato” revelam que a língua portuguesa está longe de constituir uma unanimidade nas práticas cotidianas, ocupando um lugar exógeno e distante para muitos indivíduos timorenses. As relações de poder em suas instâncias macro e micro (FOUCAULT, 1997) produzem a emergência de uma língua que atenda interesses diversos, cumprindo inclusive papel segregante e uma hierarquização linguística. A reflexão proposta por este trabalho consiste na problematização acerca da presença do idioma lusitano em Timor-Leste e as tensões produzidas pelas relações de poder e pelos discursos conflitantes em defesa (ou não) do idioma. $\mathrm{O}$ corpus de análise consiste, além da base documental oficial de Timor-Leste, de depoimentos (oficiais e não oficiais) de cidadãos timorenses, pertencentes a diversos grupos sociais, coletados em trabalho dos pesquisadores no país. O que se percebe é que Timor-Leste vive um dilema causado pelas questões institucionais sobre o projeto de uma lusofonia forçada o que faz com que os timorenses, em maior ou menor escala, vivenciem um apagamento de línguas, culturas e vozes nas políticas de língua adotadas.

Palavras-chave: Política linguística; Lusofonia; Timor-Leste.

\footnotetext{
${ }^{1}$ https://dgp.cnpq.br/dgp/espelhogrupo/7680902022280127.
} 
Abstract: Historical turbulences and politics related to Timor-Leste prompted a state policy decision of the co-officialization of the Portuguese language in the small Asian multilingual country. This decision, however, intends to characterize the country as Lusophone, which set the creation of a Lusophone "imagined community" (ANDERSON, 2008) since the "de facto" language policies reveal that the Portuguese language is far from being unanimous in daily practices, taking up an exogenous and distant place for many Timorese people. The power relations in their macro and micro instances (FOUCAULT, 1997), produce the emergence of a language that meets diverse interests, including a segregating role and a linguistic hierarchy. The present work proposes to reflect on the Lusitanian language presence in Timor-Leste and the tensions produced by power relations and the conflicting speeches defending (or not) the language. The corpus of analysis consists of official documents of Timor-Leste, testimonials (official and unofficial) of Timorese citizens from different social groups and backgrounds, collected in the work by researchers in the country. What is noticeable is that Timor-Leste is in a dilemma caused by institutional questions about the design of forced Lusophony, what makes the Timorese people, to a greater or lesser extent, to experience an exclusion of languages, cultures and voices in their society by the adopted language policies.

Keywords: Language policy; Lusophony; Timor-Leste.

\section{Introdução}

A questão central deste trabalho é abordar, ainda que de forma sucinta, a problemática que cerca uma categoria como a língua em contextos coloniais, pós-coloniais e "neocoloniais". Particularmente, este estudo visa confrontar discursos e trazer à tona tensões e relações de poder advindos da escolha política do Estado de Timor-Leste por conta da oficialização da língua portuguesa em sua Constituição Federal em 2002.

Obviamente que, por trás desta tentativa, está uma realidade que não pode ser desconsiderada e que é capital nos estudos político-linguísticos: as gentes. Utilizada em diversas estratégias nos processos de colonização, quer como forma de dominação, quer como aliada para a invenção das nações, como apagamento e reforço de identidades, ou 
ainda como espólio de guerra, a questão da gestão da língua, tratada geralmente como problema, consiste - em contextos como Timor-Leste, por exemplo - em uma atribuição da administração pública, com complexidades tais que precisam ser observadas não só do ponto de vista institucional, mas também do ponto de vista político-linguístico. A "pluralidade da singularidade" ou a "invenção das línguas" (MAKONI; PENNYCOOK, 2007), assim como a "singularização da pluralidade" ou o "apagamento das diferenças" (SEVERO; SITOE; PEDRO, 2014) consistem em discussões fundamentais que contemplam contextos multilinguísticos/multiculturais pós-coloniais, onde ainda resistem heranças do colonialismo hegemônico e que servem aos projetos de criação das nações unificadas em suas línguas oficiais.

No período pré-colonial, conforme Belo (2013), a história de Timor-Leste mostra um país composto por 54 reinos com costumes, línguas e identidades próprias, bem como com disputas decorrentes de questões territoriais e linguísticas envolvendo as 15 línguas (mapeadas) do país. No início do século XVI, com a chegada dos portugueses, Timor-Leste experimenta um longo período colonial no qual a língua portuguesa e a Igreja Católica interferem na dinâmica social dos timorenses por conta da execução do projeto colonial do Império Português, realizado com mais afinco a partir do século XVII, de acordo com Durand (2009).

Após um período de 25 anos (1975-1999) sob o domínio da Indonésia, durante o qual Timor-Leste vivenciou massacres terríveis que dizimaram dois terços da população, o povo decidiu, por meio de um plebiscito, pela autonomia do território em relação ao país vizinho insular. Com ela, sob a tutela do governo provisório da ONU, as elites política e intelectual do país organizaram suas prerrogativas constitucionais, bem como pensaram em um projeto de Nação para os leste-timorenses. A ideia de se constituir como Estado autônomo e independente, além de proteger os patrimônios identitários materiais e imateriais do país, produziu escolhas estatais tendo em conta a condição do país em situação pós-conflito, o seu contexto multicultural e as pretensões para o futuro do país no contexto mundial globalizado. A independência foi restaurada em $2002^{2}$ e, com ela, a Constituição do país foi elaborada, afetando diretamente o Planejamento Estratégico do Estado em seus mais variados documentos normativos, tais como o Plano Nacional de Educação e o Plano de Carreira Docente.

\footnotetext{
${ }^{2}$ Após a saída da Indonésia do território, Timor-Leste foi administrado pelas Nações Unidas (1999-2002).
} 
A institucionalização do idioma lusitano, a partir dos documentos oficiais de Timor-Leste retrata um projeto estatal, com apoio de diversas instituições estrangeiras, visando delimitar um espaço geopolítico com pretensões lusófonas em meio às forças das potências internacionais da Indonésia, da Austrália - em maior escala - e da China - de forma distinta, mas não menos ameaçadora. ${ }^{3}$ Entretanto, aquilo que se organiza no plano do ideal entra em confronto com as práticas vivenciadas no cotidiano do país. As dinâmicas dos usos linguísticos timorenses no cotidiano, consideradas por nós como "políticas linguísticas de fato", não corroboram aquilo que lhes foi imposto pelo Estado e que configura o que chamamos de "políticas linguísticas de direito".

Portanto, este trabalho brevemente situará as escolhas linguísticas para TimorLeste, tanto do ponto de vista histórico, quanto com os direcionamentos teóricos escolhidos para as reflexões propostas. Em seguida, discutirá as relações entre "nacionalismo" e "lusofonia" e suas implicações no país para, num momento final, buscar uma possível análise quanto aos dilemas político-linguísticos vivenciados em Timor-Leste, ilustrando essas reflexões com depoimentos de timorenses coletados durante nossa atuação como professores de língua portuguesa no país, no programa de cooperação internacional Programa de Qualificação de Docentes em Língua Portuguesa (PQLP)/Capes.

\section{A oficialização da língua portuguesa em Timor-Leste}

Assim como nos países de colonização portuguesa em África, durante o processo de constituição do Estado-Nação leste-timorense, a língua portuguesa foi co-oficializada em Timor-Leste, evidenciando uma necessidade de criação de uma unidade nacional e de "expressão de valores democráticos" (BEREMBLUM, 2003, p. 33), o que, de acordo com essa autora, viabiliza a gestão política e territorial única, sobretudo em contextos de diversidade linguística e cultural, caso de Timor-Leste. Beremblum (2003, p. 33) nos explica ainda que o termo nação representa "o vínculo mais universal de comunhão entre seres humanos [...]. É quando a nação se vincula a um Estado particular a este, à soberania popular e as nações associam-se a territórios”.

\footnotetext{
${ }^{3}$ Vale, aqui, o destaque para o fato de que a Constituição da República Democrática de Timor-Leste de 2002, por conta da oficialização da língua portuguesa, promove a admissão do país na Comunidade dos Países de Língua Portuguesa - CPLP -, bem como expõe à toda comunidade internacional um plano claro de defesa e de soberania nacionais, frente às ameaças estrangeiras - sobretudo relacionadas à questão petrolífera.
} 
Entendemos que a ideia de nação como uma "comunidade imaginada" (ANDERSON, 2008) vem ao encontro da noção de "invenção das línguas" (MAKONI; PENNYCOOK, 2007), dado que na criação dos Estados-nação, a relação "um Estado, uma língua, uma nação" favorecia a unificação de povos e territórios capturados por uma mesma ideologia dominante. No sentido de garantir a atuação e a penetração dessa ideologia dominante nas sociedades dominadas, os "Aparelhos Ideológicos de Estado" (ALTHUSSER, 1980) tornam-se grandes ferramentas de controle e governo, operando nas massas de forma pontual como: a Educação, o Sistema Jurídico, a Cultura, entre outras formas de condução de um projeto nacionalista. $\mathrm{O}$ nacionalismo pretendido pelos projetos estatais é complexo e merece cuidadoso apreço. Bresser-Pereira (2008, p. 171) declara ser o nacionalismo "[...] uma ideologia sob suspeita [...] uma vez que bem atende às necessidades de países ricos."

Levando-se em conta que Timor-Leste viveu cinco séculos de colonialismo português e, quando pretendeu-se independente em 1975, foi brutalmente invadido pela Indonésia, o que causou estragos de toda sorte, inclusive linguísticos para o país, a necessidade de, após os 25 anos de dominação, retomar a independência do país era uma questão capital. Isso também envolveu a busca por uma marca linguística no escopo dos ideais de uma "Nação Timorense" e uma "Identidade Nacional", o que firmou-se em argumentos que confluíam para o discurso de que a lusofonia seria uma boa opção para o país.

Stuart Hall (2005, p. 64) afirma ser o nacionalismo "um discurso [...] cujos sentidos constroem identidades." Sendo assim, um discurso baseado em tradições sustenta a construção de identidades pretendidas pela ideologia dominante, lembrando que essa formação de uma identidade cultural nacional se constroi a partir de uma arena de poderes em conflito. As forças convergentes e divergentes que circulam nas arenas sociais de poder "coexistem e se apoiam umas nas outras [...] consistindo em uma teia de circulação de poderes em disputa por privilégios." (FOUCAULT, 1997, p. 71). Isso equivale a dizer que, apesar de existir uma ideologia dominante, esta se prevalece de outras forças ideológicas existentes na sociedade, as quais tanto auxiliam no processo de domínio, quanto provocam resistências e movimentos antitéticos com relação ao domínio.

Com relação ao discurso da tradição, por exemplo, o qual muitas vezes é usado e construído para sustentar ideologias e atos políticos oficiais, Hobsbawn e Ranger (2015, p. 17) explicam que são, as tradições, algo igualmente inventado, sobretudo pelas teias 
de poderes coloniais, e que possuem algumas peculiaridades, tais como: i) simbolizam a tentativa de coesão social; ii) legitimam instituições; iii) produzem status e relações de autoridade; iv) inculcam ideias e sistemas de valores; bem como v) regulam padrões de comportamento. No caso da arena de conflitos que se forma em torno do discurso da tradição, a ideologia dominante movimenta forças no sentido de resgatar elementos do passado histórico que corroboram com as intenções políticas do presente, enquanto que as forças subjugadas, em movimento de defesa, criam suas próprias tradições, usando processos históricos semelhantes, ainda que com suas próprias peculiaridades.

Em vista disso, e considerando o que foi propiciado pela formação das nações, o olhar para o que se entende por "lusofonia" exige cautela e criticidade evitando o que Margarido (2000, p. 6) chama de "amnésia coletiva” causada pela invenção da lusofonia e atentando para o que nos adverte Lourenço $(1999$, p. 76$)$ ao dizer que: "Poucos países fabricaram acerca de si mesmos uma imagem tão idílica como Portugal." As "marcas do projeto de tradição colonial” (MAKONI; SEVERO, 2015, p. 89) são sensíveis em diversas situações nos países colonizados por Portugal, sobretudo no tocante à colonização linguística (MARIANI, 2004).

A oficialização da língua portuguesa traz para as ex-colônias lusitanas, conforme Severo, Sitoe e Pedro (2014, p. 24), alguns efeitos que incluem o "amortecimento do prestígio social e simbólico das demais línguas locais", assim como um processo de "hibridização da língua do colonizador com as línguas nacionais". Os movimentos de "amortecimento" e "hibridização" mencionados refletem as ações das forças dominantes e a resistência dos subalternos. No caso de Timor-Leste, por exemplo, persiste um discurso - de escritores e pesquisadores locais e do exterior, inclusive - de que o tétum - língua nacional e co-oficial do país - é considerado "primitivo", incapaz de expressar os conhecimentos técnico-científicos, além de supostamente limitar as possibilidades comunicativas do país com a comunidade internacional. Esse discurso, construído com argumentos inconsistentes para a ciência linguística, reproduzem preceitos coloniais que abrangem a imprescindibilidade da língua portuguesa para o êxito do projeto nacional idealizado para Timor-Leste.

A estratégia de co-oficialização da língua portuguesa define, então, políticas linguísticas de/para Timor-Leste valendo-se do suporte jurídico constitucional para sua imposição, tal como explicitado por Calvet (2007, p. 75 ). Conforme o autor, a funcionalidade 
de um idioma definida constitucionalmente repercute no projeto linguístico pretendido para um país, projeto esse embebido das ideologias políticas vigentes. Entretanto, o próprio Calvet reconhece a fragilidade dessa estratégia uma vez que aquilo que é organizado in vitro (ou de direito) precisa ser sustentado por práticas in vivo (ou de fato), ainda que esse conceito também seja produzido a partir de um olhar discursivo.

No caso de Timor-Leste, as perspectivas político-linguísticas in vitro e in vivo não comungam das mesmas dinâmicas e orientações. Na verdade, dentro do que se pode entender como as dinâmicas in vitro e in vivo, há múltiplas forças concorrentes que tentam se sobrepor umas às outras na disputa por espaços de legitimação de seu(s) poder(es). Conforme Quijano (2005, p. 121),

\begin{abstract}
A incorporação de tão diversas e heterogêneas histórias culturais em um mundo único [...] significou [...] uma configuração cultural, intelectual, em suma, intersubjetiva, equivalente à articulação de todas as formas de controle do trabalho em torno do capital.
\end{abstract}

Essa prática colonial de unificação, ainda hoje, persiste e dela repercutem imposições políticas, culturais e linguísticas.

Problematizando a visão jurídica de políticas linguísticas, uma prova de que decretos linguísticos não definem as práticas linguísticas é dada pela realidade constitucional timorense em contraponto às vivências linguísticas do país. Apesar da Constituição da República em seu artigo $159^{\circ}$ estabelecer a co-oficialização das línguas portuguesa e tétum, bem como denominar o inglês e a bahasa indonésia como "línguas de trabalho" para atuarem "na administração pública enquanto tal se mostrar necessário", Timor-Leste apresenta o uso mais frequente de uma variante do tétum (conhecida como tétum prasa ou tétum dili) ${ }^{4}$ a qual abarca grande número de empréstimos linguísticos. Evidencia-se, também, em alguns espaços e situações sociais, o uso da língua portuguesa, porém é constante a presença da língua indonésia nos ambientes públicos, assim como a ocorrência de usos da língua inglesa fora das determinações constitucionais é bastante comum - um

\footnotetext{
${ }^{4} \mathrm{O}$ Tétum antigo - Tétum Terik - sofreu estruturalmente diversas modificações (sobretudo lexicais) como produto da proximidade de convivência com a língua portuguesa, fundamentalmente, mas também sofreu influências do indonésio e do inglês. A esse Tétum é dado o nome de Tétum Prasa (praça).
} 
legado dos 10 anos de presença da Organização das Nações Unidas no país. Isso sem contar com o uso das línguas autóctones em regiões e situações sociais específicas.

Sendo assim, a escolha pela língua portuguesa determinada pelos documentos oficiais, no escopo de um projeto de nacionalismo lusófono pretendido para Timor-Leste, reforça as marcas de um passado histórico colonial, o qual procura se sustentar em uma suposta identidade lusófona, mascarando uma realidade multilíngue e multicultural que constitui aquilo que Thomaz (2002) classificou como Babel Lorosa'e. Gellner (1983 apud Bresser-Pereira, 2008, p. 180) esclarece que o nacionalismo, tal como aqui se apresenta, significa a "imposição de uma alta cultura em uma sociedade onde predominavam baixas culturas na maioria, se não na totalidade, da população [...] a difusão de um idioma para comunicação tecnológica midiatizado pela escola e burocraticamente supervisionado".

As razões que motivaram as escolhas político-linguísticas para Timor-Leste apontam para uma coesão nacional em torno de um nacionalismo pretendido, como forma de circunscrição geopolítica da nação no cenário global e proteção diante de ameaças históricas sofridas pelo país. Esse projeto de nacionalismo lusófono sustenta-se discursivamente em políticas e argumentos que são passíveis de problematização, o que se pretende fazer na próxima seção.

\section{O Nacionalismo e a Lusofonia em questão}

Anderson (2008) define a nação como uma comunidade imaginada, a qual, mais do que um território limitado espacialmente por fronteiras, só existe porque evoca imagens e percepções comuns às várias comunidades:

\footnotetext{
Ela é imaginada porque mesmo os membros da mais minúscula das nações jamais se conhecerão, encontrarão ou nem sequer ouvirão falar da maioria de seus companheiros, embora todos tenham em mente a imagem viva da comunhão entre eles. (ANDERSON, 2008, p. 32).
}

Para imaginar a nação, a língua cumpre um papel fundamental. Foi a partir do surgimento da impressão, de acordo com o autor, que se possibilitou o nascimento do naci- 
onalismo (p. 190), pois, com o desenvolvimento da tipografia e da capacidade de publicação dos periódicos, o mundo passa a experimentar o sentimento de nacionalismo. Anderson quis demonstrar a importância dos textos impressos e do letramento a serviço de uma estabilização nacionalista, bem como a unificação de línguas e culturas em uma língua uma nacional.

O conceito de Estado-nação deve ser revisto e problematizado constantemente, sobretudo por conta dos movimentos de pessoas que constroem o que pode ser denominado como uma transnacionalização. Consequentemente, a ideia de nacionalismo também precisa ser repensada, assim como o "sentimento nacionalista" nos países de passado colonial que sofreram a transformação em Estados nacionais no século XX. O fenômeno da transnacionalização e o legado do passado colonial tornam-se variantes complexas que interferem sobremaneira na formação do Estado moderno. Timor-Leste, um exemplo de país que vivenciou esses dois fenômenos mencionados, decidiu aderir ao chamado "mundo lusófono", utilizando-se da língua portuguesa como idioma oficial, para, apesar de sua pluriculturalidade, se estabelecer como "nação irmã” das demais que compõem a Comunidade dos Países de Língua Portuguesa (CPLP).

O cientista político Bresser-Pereira (2008) aborda o nacionalismo como uma ideologia capitalista cujas consequências podem ser prejudiciais ao regime democrático caso seu projeto seja conduzido com radicalismo. Segundo o autor, o nacionalismo é uma ideologia de origem burguesa, entretanto, com forte apelo popular, já que só se constitui "quando capitalistas, trabalhadores e classe profissional superam de alguma forma seus conflitos internos, partilham um destino comum e se solidarizam na competição com as demais nações" (BRESSER-PEREIRA, 2008, p. 171-172). Entender, com a cautela apregoada pelo autor, as ideias nacionalistas declaradas em discursos oficiais, bem como observar a fala de cidadãos - as quais nem sempre são ouvidas ainda que em uma democracia estabelecida -, pode nos trazer reflexões importantes sobre os caminhos escolhidos pelos projetos linguísticos estatais e suas práticas cotidianas.

Essa suspeita crítica sobre a ideia de nacionalismo nos faz olhar para os discursos oficiais de Timor-Leste, bem como para os não oficiais. Ambos revelam caminhos ideológicos (e identitários) que nem sempre estão em consonância. Segundo Bresser-Pereira, no capitalismo tecno-burocrático de hoje, há um apoio estrutural nas famílias, organizações e estados-nação no qual "o papel social que se espera de cada indivíduo é que se 
solidarize - que 'vista a camisa' da sua família, das organizações empresariais e associativas de que participa, e de seu estado-nação” (BRESSER-PEREIRA, 2008, p. 187).

Isso reflete a circulação de poderes, explicada por Foucault (1997), os quais não se concentram em uma força dominante, mas circulam entre esta e suas capilaridades na rede social. Sendo assim, povo e Estado, ainda que não se tratem de blocos homogêneos, possuem participação no sistema social e no projeto nacional, sobretudo por conta de estratégias biopolíticas de controle dos governos sobre os indivíduos. No caso timorense, há um apelo imbricado em falas oficiais e não oficiais, o qual produz discursos que sustentam a ideia de a língua portuguesa ser uma espécie de passaporte aos anseios do Estado e um aceno de melhores condições de vida à população.

O líder do movimento de resistência à invasão Indonésia, Kay Rala Xanana Gusmão - ex-Presidente da República de Timor-Leste e ex-Primeiro-Ministro de TimorLeste em 5 mandados sucessivos intercalados - proferiu um discurso (GUSMÃO, 2011), em 2011, reforçando o já em andamento projeto de sensibilização nacional que foi levado à comunidade internacional tanto com a intenção de assegurar e reforçar parcerias e investimentos externos, quanto de buscar o equilíbrio e fortalecimento político interno. Gusmão realça a história do país na qual "o povo timorense começou dignamente a luta por uma nova vida, a luta por melhores condições pelas quais sonhava”. O político assume-se porta-voz do povo timorense, o que simbolicamente representa, ou quer representar, um discurso único de seu povo sob a guarda de um projeto de Nação já estabelecido pela elite política do país na Constituição de 2002, cujo "slogan” de governo ainda vigente é "Adeus conflito, bem-vindo desenvolvimento". O tom apelativo retrata uma suposta hegemonia pretendida com uso do enunciado "povo timorense" quanto aos seus anseios nacionais. Ainda que todos obviamente queiram a paz, o conceito de "desenvolvimento" é de ordem político-capitalista, suspeita e questionável. A busca por um desenvolvimento único pauta-se na ideia de uma situação frágil da população recém-saída de um conflito severo, a qual supostamente acataria qualquer sugestão no comportamento social que negasse a guerra, a fome ou a morte, sem a percepção do risco premente de apagamento cultural em detrimento de um desenvolvimento econômico "a qualquer custo”.

Uma cultura nacional, conforme Hall (2005), é um discurso - um modo de construir sentidos que influencia e organiza tanto as ações humanas quanto a concepção que 
os indivíduos possuem de si próprios. É necessário, portanto, problematizar um projeto de cultura nacional observando, segundo Hall, as forças políticas pertinentes à construção das "identidades pretendidas" (HALL, 2005, p. 65). Os conceitos de "nação" e "nacionalismo" sustentam discursos sobre "cultura(s) nacional(is)" muitas vezes de forma tendenciosa. Anderson (2008) alerta que o "nacionalismo" não pode ser tratado como os demais "ismos" os quais produziram "seus próprios pensadores", mas como uma categoria semelhante à de "parentesco" ou "religião”. Dessa forma, segundo Anderson, a "nação" consistiria em "uma comunidade política tanto imaginada como inerentemente limitada e soberana" (HALL, 2005, p. 23). Os defensores do nacionalismo, conforme Anderson, geralmente buscam suas raízes nacionais em tempos imemoriais, em tradições, crenças identitárias entre outras manifestações próprias de uma determinada sociedade. Por sua vez, Hobsbawn e Ranger (2015, p. 11), adverte que "a invenção de tradições é essencialmente um processo de formalização e ritualização, caracterizado por referir-se ao passado, mesmo que apenas pela imposição da repetição".

Em Timor-Leste, por exemplo, os símbolos nacionais, tais como a bandeira, o hino nacional, o brasão da República e o estatuto de línguas oficiais, foram inventados no sentido de identificar oficialmente o país no cenário internacional, sendo que cada um desses símbolos recupera estrategicamente aspectos da história do país e de seu povo. O vermelho da bandeira, por exemplo, remete ao sangue derramado em defesa do país - que está ligado à figura dos "heróis nacionais", mencionados no hino e simbolizados pelas armas que compõem o brasão da República. O hino traz a letra em língua portuguesa e enaltece a força dos timorenses contra o colonialismo e o imperialismo. Para além dos elementos oficiais há os elementos culturais que, transformados em símbolos nacionais, são, inclusive, comercializados como elementos de identidade timorense, como o tecido tradicional - tais - , a casa sagrada - uma lulik - ou a figura (sagrada) do crocodilo-lafaek. Todos esses elementos, oficiais ou culturais, foram discursivisados a partir do viés da tradição que vinha ao encontro do projeto de unificação nacional. Entretanto, o contexto multiétnico timorense é suficiente razão para que, por exemplo, a ideia de "casa sagrada" não seja a mesma para todos os grupos étnicos, assim como a multiculturalidade do país garante diferenças significativas quanto à produção, uso e função de elementos considerados "tradicionais", como a vestimenta ou a mitologia. Nesse escopo plural, a categoria 
"língua” também não comporta-se de forma diferente, o que explica um processo de discursivização de uma tradição linguística inventada para um projeto de unificação nacional.

Nas sociedades industriais, os Estados-nação estão voltados para a industrialização ou para o desenvolvimento econômico e as alterações e adaptações sociais decorrentes. Os Estados precisam estabelecer códigos de comunicação entre todos os seus membros, que permitam alcançar uma produtividade crescente. Para dar cabo das mudanças almejadas para a nação, novas tradições são constantemente inventadas, "prontamente enxertadas nas velhas $[. .$.$] outras vezes [. .$.$] inventadas com empréstimos fornecidos pelos de-$ pósitos bem supridos do ritual, simbolismo e princípios morais oficiais" (HOBSBAWN; RANGER 2015, p. 13) Nesse sentido, Bresser-Pereira (2008) aponta que uma mesma língua é uma quase-necessidade, e a educação pública, uma necessidade absoluta, porque essas ajudam a definir os símbolos de comunicação social comuns e permitem o aprendizado de formas cada vez mais avançadas de produção, objetivo maior do sistema capitalista.

Sobre os mecanismos do Estado em assegurar a reprodução das forças de trabalho e garantir a produção, Althusser (1980) explica que o meio material de os governos conseguirem essa garantia dá-se pelo salário. Entretanto, há outros valores imateriais, organizados pelos aparelhos ideológicos do Estado, os quais cumprem papel semelhante ao ganho salarial e que Bourdieu (1982) chama de "capital simbólico”. Segundo Althusser (1980, p. 22), as instituições estatais “ensinam 'saberes práticos' mas em moldes que asseguram a sujeição à ideologia dominante ou o 'manejo' da prática desta.” Em consonância com essa linha de raciocínio, a língua portuguesa representa importante capital simbólico para os indivíduos das terras colonizadas por Portugal, garantindo-lhes privilégios diversos estabelecidos de forma institucional desde os tempos coloniais. ${ }^{5}$ Atualmente, a língua do colonizador continua sendo um importante capital simbólico, formador de elites nos países de passado colonial, garantindo privilégios aos indivíduos que a dominam, como o acesso a universidades, a conhecimento científico, à literatura e outros bens imateriais.

\footnotetext{
${ }^{5}$ São muitos os documentos coloniais que estabelecem diferenças entre os colonizados que não sabem o idioma europeu (indígenas) e os que o dominam (assimilados), tais como: Estatuto Político, Social e Criminal dos Indígenas de Angola e Moçambique, de 1926; o Acto Colonial, de 1930; a Carta Orgânica do Império Colonial Português e Reforma Administrativa Ultramarina, de 1933; o Estatuto dos Indígenas Portugueses das Províncias da Guiné, Angola e Moçambique, aprovado por Decreto-lei de 20 de maio de 1954.
} 
Timor-Leste vivencia hoje essa realidade de possuir uma elite intelectual e política que, pela experiência na diáspora durante a invasão indonésia ou pela categoria de "assimilados" adquirida no passado colonial, detém o poder dominante local, o acesso aos saberes acadêmicos e os privilégios sociais e políticos garantidos na lei. Há, inclusive, incentivos salariais no plano de carreira docente nacional aos professores que tiverem o domínio do idioma. Estes, comumente, assumem posições de destaque na gestão nacional da Educação, garantindo, portanto, os meios de reprodução da força de trabalho em prol da criação de uma nação lusófona.

Torna-se relevante retomar a ideia foucaultiana de biopoder, o qual atua diretamente, com mecanismos peculiares, na construção de saberes, na elaboração de ações estatais normativas, na legitimação de discursos com valor de verdade, entre outras formas de manifestação. Diversos segmentos sociais como a mídia, as igrejas, os aparelhos estatais, a escola, propagandeiam aquilo que é pretendido pela ideologia dominante, estabelecendo o comportamento normal, os modelos de corpo e de saúde a serem seguidos, os valores morais, o procedimento correto dos que anseiam um bem comum para todos etc. O Estado assume o biopoder não sobre um indivíduo, mas na administração do corpo da população, criando técnicas de governamentabilidade que visem ao crescimento das cidades, ao desenvolvimento "sem conflito" - como em Timor-Leste - às melhorias de condição de vida da sociedade (infraestrutura, saúde, educação, segurança etc.).

O biopoder pode, como discutido até aqui, utilizar da lusofonia, por exemplo, como uma técnica de governamentabilidade que produz diversos discursos para se estabelecer em um contexto como o de Timor-Leste, representando uma ideologia estatal em um projeto de unificação nacional e de um nacionalismo altamente questionável. $\mathrm{Na}$ próxima seção, serão discutidas as controvérsias e dilemas criados por conta do projeto estatal para o nacionalismo timorense e suas políticas oficiais de língua que vai de encontro a outras políticas linguísticas residentes no campo extraoficial.

\section{As políticas de fato e as políticas de direito: os dilemas linguísticos timorenses}

Estudos da chamada linguística aplicada crítica (CANAGARAJAH, 2005; MAKONI; PENNYCOOK 2007; MAKONI; SEVERO 2015; PENNYCOOK, 2001, 2007, 2010; RAJAGOPALAN, 2003; LOPES DA SILVA; RAJAGOPALAN, 2004) remetem 
ao fato de que, na construção de políticas linguísticas nacionais, deve-se considerar a possibilidade dessas serem afetadas pelas práticas de seus falantes. É nesse sentido que Shohamy (apud MACALISTER, 2013, p.25) nomeia tais práticas como política linguística de facto, ou seja "o que realmente ocorre em uma sociedade".

Em um território plurilíngue, como Timor-Leste, a política linguística institucional, apesar de priorizar as línguas denominadas oficiais pela Constituição da RDTL tétum e português - mostra-se insuficiente para abarcar a diversidade das práticas linguísticas locais. Por isso, é necessário perceber que tipo de diálogo a política institucional se propõe a desenvolver com as práticas cotidianas. Esse diálogo pressupõe um enfrentamento ideológico com conflitos, resistências e imposições dos dois lados, o que pode ajudar a perceber que nem sempre a política linguística dita oficial coincide com a de

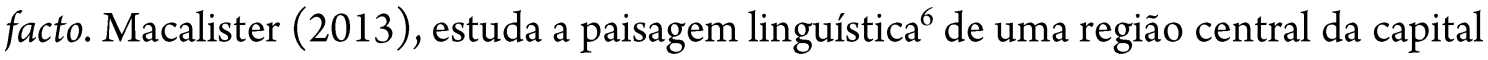
de Timor-Leste, Díli, no intuito de evidenciar marcas desse conflito de ideologias elembra que

Em alguns domínios da vida humana, ocorre uma lacuna entre o que é pretendido e o que é alcançado. A política linguística é um desses domínios, já que, enquanto as políticas linguísticas são expressões de resultados pretendidos, as práticas linguísticas nem sempre refletem essas intenções. (MACALISTER, 2013, p. 25).

Na verdade, os documentos que tratam da definição de uma política linguística institucional em Timor-Leste se preocupam quase que unicamente com o processo educacional, o que permite dizer que o aparelho ideológico da Educação consiste em mecanismo fundamental para o desenvolvimento das políticas linguísticas no país. A língua, para os governantes timorenses, é entendida como "meio de instrução", conforme pode ser observado na Lei de Bases da Educação de Timor-Leste, que prevê em seu artigo $8^{\circ}$ : “As línguas de ensino do sistema educativo timorense são o tétum e o português". Mas para além dessa visão instrumental, há que se considerar que a categoria língua não pode ser considerada com um ente único, estático e isolado da práxis de seus falantes. Ofelia

\footnotetext{
${ }^{6}$ Para Landry e Bourhis (1997), o termo paisagem linguística remete a “[...] língua dos sinais das ruas públicas, placas de propaganda, nomes de rua, nomes de locais, sinais de lojas comerciais e sinais públicos em prédios governamentais se combinam para formar a paisagem linguística de um determinado território, região ou aglomeração urbana.” (LANDRY; BOURHIS, 1997, p. 25).
} 
Garcia e Li Wei (2013) propõem, por exemplo, o conceito de translanguaging, que elegeria como alvo educacional as práticas comunicativas que hibridizam línguas. Vale lembrar que o próprio tétum - uma língua franca imposta como local devido a fatores históricos e políticos - é em si mesmo uma hibridização com o português e, por vezes, com a língua indonésia e o inglês.

Basear as políticas voltadas para a gestão linguística exclusivamente no campo educacional por meio da compreensão da língua como um artefato instrumental é desconsiderar a heterogeneidade e a dinâmica intrínsecas à língua, já que, antes de ser um meio de instrução, ela está relacionada com a constituição de identidades e afirmação cultural. Voltando a Shohamy, Ribeiro da Silva (2013) ressalta a observação da autora de que as políticas linguísticas oficiais e a real política linguística em funcionamento nas sociedades caminham descompassadas. Para efeitos deste artigo, compreendemos que esse descompasso sinaliza para contradições ideológicas e para relações assimétricas de poder que a ideia de "lusofonia" pode mascarar, uma vez que

[... ] as políticas linguísticas de fato são determinadas alhures por um conjunto de mecanismos que, indiretamente, perpetuam as PLs [Políticas Linguísticas] e que servem como instrumentos para converter ideologias, principalmente em estados-nação tradicionais, em políticas homogêneas e hegemônicas. (SHOHAMY apud RIBEIRO DA SILVA, 2013, p. 313).

Na realidade percebida em Díli, o resultado deste confronto ideológico é um paradoxo entre o institucional e o de facto. Os depoimentos recolhidos ${ }^{7}$ entre timorenses em Timor-Leste e no Brasil sobre a percepção acerca da língua portuguesa no território timorense, ao mesmo tempo que corroboram a visão institucional da decisão inscrita na Constituição - como uma maneira do país marcar uma diferença na região asiática onde se localiza e também por ser uma "herança" do antigo colonizador luso - revelam tensões entre essa visão constitucional e a utilização das línguas tétum e regionais.

\footnotetext{
${ }^{7}$ Os pesquisadores, no âmbito de suas experiências profissionais, tanto como professores de língua portuguesa em Timor-Leste através do PQLP/Capes - como no Brasil, em contato com alunos timorenses nos programas de pós-graduação da UFSC, coletaram diversos depoimentos de timorenses pertencentes a distintos grupos sociais, no intuito de recolher material para análise posterior, no tocante aos seus interesses de pesquisa.
} 
Para melhor refletirmos sobre o assunto, traremos falas de timorenses que demarcam a problemática sob pontos de vista distintos, que nos possibilitam “ouvir” vozes não oficiais desse contexto. Recorremos, primeiramente, a um extrato de uma entrevista realizada com um estudante timorense que está desenvolvendo seu mestrado no Brasil:

Timor-Leste é em primeiro lugar nós utilizamos a língua malaio, ou mais conhecido lá é língua indonésia. [...] Mas depois de restauração da independência 2002, o nosso governo escolheu a língua portuguesa é a língua oficial, mas [...] neste momento utiliza a escola básico até a escola médio todo utiliza a língua portuguesa, mas na universidade utiliza língua mistura, maior parte utiliza a língua malaio e explica como a língua tétum, porque língua tétum é segunda língua oficial do Timor-Leste depois de língua portuguesa. [...] escrevemos a língua portuguesa, depois explica como língua malaio ou língua tétum para os alunos melhor compreender. (Depoimento de um estudante timorense em Florianópolis, dezembro de 2013).

Nota-se na fala do estudante acima, uma lacuna entre a adoção da língua portuguesa e seu uso efetivo na escola. Pois, conforme está dito no trecho "escrevemos a língua portuguesa [ou seja, o que é escrito está em língua portuguesa], depois explica como língua malaio ou língua tétum [o que é oralizado, é feito em outros idiomas] para os alunos melhor compreender", o entrevistado reconhece a dificuldade dos alunos perceberem o conteúdo por meio da língua portuguesa, por isso é necessário recorrer à língua malaia (que na Indonésia se transformou em bahasa indonésio, ou língua indonésia, para efeitos de oficialização após a Independência do país). Além disso, atente-se para o termo "língua mistura", que é como o entrevistado classifica as práticas linguísticas na sala de aula da universidade necessária para que os estudantes timorenses apreendam os conteúdos.

A fala de outro aluno amplia esta discussão e resume, no final, que língua deve ser utilizada na sala de aula:

Eu acho que lá Timor-Leste para transformar o meu conhecimento para todos alunos preciso bem conhece três língua. Primeiro, o português; segundo, língua malaio; e terceiro, língua tétum. Porque a maioria pessoa, maioria estudante lá Timor-Leste talvez não entenda bem português. Por isso, para facilitar entendimento dele e talvez com língua português 
quando eles não entende bem, talvez através de língua tétum; quando língua tétum ele não entende bem talvez com língua, língua malaio. Mas quando a pessoa que tem conhecimento sobre língua inglês pode ser através de língua inglês. Baseado na necessidade das pessoas que encontremos [...] na sala de aula. (Depoimento de um estudante timorense em Florianópolis, dezembro de 2013).

Ou seja, a fixação das línguas tétum e portuguesa como oficiais não é definidora do seu uso real mesmo no sistema educativo, ainda que sejam esses idiomas, conforme dito antes, línguas previstas como "de instrução". O que acontece na prática é a expressão linguística conforme a "necessidade das pessoas", ou a familiaridade que cada indivíduo possua com determinada língua. Observamos assim que, a partir da prática - a busca pela compreensão das aulas - é que se estabelece o uso da língua e não o contrário, ou seja, não é a política institucional, por meio de uma lei, que se consagra como a viabilizadora desse empreendimento.

Fora do ambiente da sala de aula, a realidade também é distinta e merece olhar cauteloso quanto às dinâmicas e linguísticas do país. Abaixo seguem três excertos de depoimentos de cidadãos timorenses coletados no âmbito de nossa atuação naquele país.

Eu não falo português porque não preciso. Acho bonito quem fala essa língua, mas eu falo língua tétum e língua indonésia no meu trabalho, com meus amigos, para ir ao mercado ou andar de microlet. A língua portuguesa é só para falar com os portugueses e brasileiros, porque está na Constituição. (Uma comerciante, de 43 anos - depoimento concedido em língua tétum, traduzido pelos pesquisadores).

A indonésia acabou com a língua portuguesa em Timor-Leste e muitos timorenses têm medo de falar essa língua ainda hoje. Na minha opinião ela não faz falta. Quem tem que se comunicar com estrangeiros usa a língua, mas os estrangeiros também podem aprender a nossa língua, não podem? Assim é que é bem melhor! (motorista do Ministério da Educação, 52 anos).

Eu fala pouco a língua português... só que é língua oficial de Timor-Leste... eu usa a língua tétum e bahasa indonésia nas dias... e a língua makasae quando vou ao distrito visitar as famílias. (vendedora ambulante, não sabia a idade). 
As falas remetem ao não uso, ou à não necessidade, da língua portuguesa em Timor-Leste sob aspectos distintos. Trata-se do ponto de vista de três cidadãos com pouca ou nenhuma escolaridade e que conduzem as suas vidas sem dependerem do idioma lusitano, ainda que, como no caso da vendedora ambulante, o idioma possa representar alguma vantagem no exercício de seu trabalho. São pessoas que passaram pelos três períodos políticos do país - colonialismo, invasão e independência -, sobreviveram às intempéries causadas por todos e possuem um posicionamento crítico claro. $O$ fato é que, assim como esses timorenses, milhares de outros vivem (e vivem bem) as suas vidas apesar do projeto lusófono pretendido para o país, não se sentindo, inclusive, como pertencentes a essa lusofonia, dado que a língua portuguesa é "para falar com estrangeiros". Esta afirmação, particularmente, remete ao estatuto de "língua estrangeira” que a língua portuguesa representa para muitos timorenses que a utilizam em situações específicas de comunicação com indivíduos que não pertencem ao seu universo cultural.

A agência das pessoas das comunidades linguísticas na definição de uma política linguística institucional, que reflita a política linguística de facto, leva, no campo teórico, Rajagopalan (2013) a propor que a política linguística não seja uma área circunscrita ao campo de atuação da ciência linguística, mas sim que seja um objeto da ciência política:

A política linguística consiste de uma vasta gama de atos e gestos específicos, quase todos de cunho político. A política linguística é, em outras palavras, um ramo de política e, enquanto tal, comparável a outras áreas de atuação política, tais como a política econômica, a política social, a política de habitação, de trabalho, de planejamento familiar, de alimentos geneticamente modificados, de investimentos em fontes de energia alternativa, e assim por diante. (RAJAGOPALAN, 2013, p. 34).

Ressalvada a consequência que esta proposta de mudança epistemológica pode gerar para a área da linguística, há de se considerar que a política para as línguas se beneficiaria de um maior poder democrático se se situasse no campo exclusivo da política. Retomando Rajagopalan, o autor não tira a responsabilidade do linguista para a colaboração na implementação de gestões na área da linguagem:

A política linguística é um campo de atividade onde quem tem a última palavra é o cidadão comum e não o linguista e que a única forme de o linguista participar nas discussões sobre a política linguística é na qualidade de linguista enquanto cidadão comum. [...] A língua nacional não é um 
assunto de ciência; ela pertence à esfera de política (RAJAGOPALAN, 2013, p. 23-24).

Recorrendo, então, a pesquisadores e professores de língua portuguesa timorenses, os paradoxos são reforçados e a evidente dissonância em termos político-linguísticos do país mostra-se, mais uma vez, conforme visto no depoimento abaixo:

\begin{abstract}
A Língua Portuguesa é um recurso para unirmos a nação timorense e promovermos um diálogo com as demais nações do mundo globalizado. Mas o povo tem ainda dificuldades para entender isso e se dedicar mais a aprender esse idioma. Os tradicionalismos impedem um crescimento do país e fragilizam Timor-Leste na comunidade internacional. Não estou dizendo que devemos parar de usar o Tétum [idioma oficial local] mas que usemos cada vez mais uma língua que trará mais possibilidades por ser mais desenvolvida que a nossa. (depoimento de um professor universitário e linguista timorense em Díli, julho de 2014, grifos nossos).
\end{abstract}

Se o argumento do reforço às tradições timorenses (com a implementação da Língua Portuguesa no país) entra em choque com a fala do professor com relação ao que ele chama de "tradicionalismos" (referindo-se às línguas nacionais), parece que o apelo da tradição colonial lusitana pretende-se de maior relevância que as demais heranças tradicionais. Essas tradições, apesar de reconhecidas na fala do timorense, aparentam não serem tão importantes assim, possuindo inclusive aspectos prejudiciais, uma vez que "impedem" o crescimento e o desenvolvimento do país e "fragilizam" a nação. Sabendo-se que a classe de professores universitários consiste em importante parcela da elite timorense - muitas vezes com grandes influências na política do país dadas as raízes de luta e guerrilha -, é possível perceber que a fala do timorense em questão coaduna com o projeto político nacional de massificação da língua portuguesa, com suas intenções políticas claramente expressas, bem como revela a realidade linguística da população timorense que organiza suas dinâmicas linguísticas na contramão desse projeto nacional.

Assim, se por um lado, a questão linguística timorense se sustenta em discursos oficiais que visam, em tese, o fortalecimento do país em uma nação unida pelo bem de todos, por outro lado, as ações político-linguísticas são, na verdade, atos contraditórios do Estado contra seus próprios objetivos. As dinâmicas político-linguísticas extra-oficiais re- 
velam outras ideologias que não corroboram a unificação linguística ou o projeto lusófono pretendido. Os cidadãos timorenses utilizam as mais variadas línguas de que dispõem sem que isso os faça sentirem-se "menos timorenses", uma vez que o pertencimento e os aspectos identitários não se encontram atrelados à necessidade de uso de um único idioma. Entretanto o que é estabelecido de direito revela uma série de estratagemas estatais no sentido de cooptar adeptos ao nacionalismo pretendido. $\mathrm{O}$ dilema central talvez nem esteja na divergência de interesses estabelecida, fato comum a povos e seus governos, mas às condições pelas quais aquilo que é estabelecido "de direito" possa restringir, coibir e até banir aquilo que existe "de fato". Se há "falta de entendimento", conforme dito pelo professor timorense, essa talvez não seja unilateral, nem ingênua, muito menos remeta à ignorância, mas talvez uma representação da inexistência de um diálogo entre poderes oficiais e não-oficiais no sentido democrático de uma política linguística para Timor-Leste.

\section{Considerações finais}

O estudo sobre a lusofonia perpassa o espaço interdisciplinar compartilhado por campos diversos do saber, tais como: a Linguística, a História, a Política, entre outros. Entender o fenômeno da lusofonia não é apenas entender o estatuto da língua portuguesa nos países ditos lusófonos, como Timor-Leste. Antes, é imprescindível entender os processos histórico-políticos imbricados nesse fenômeno, o qual tomado como meramente linguístico nos traz uma visão superficial, ingênua e distorcida do que de fato isso consiste.

Timor-Leste teve sua história colonial no Império Português e as heranças desse processo não são apenas linguísticas, mas também sócio-histórico-políticas, que foram atravessadas por diversos outros fenômenos sócio-históricos igualmente relevantes para a constituição do cenário multilíngue complexo do país asiático. O passado de inúmeros reinos conflitantes, a lógica oriental de organização humana e social, a sanguinária invasão japonesa na segunda guerra mundial, os 25 anos de invasão brutal da Indonésia e o recente processo de democratização com seu projeto de Nação independente são alguns dos principais fatos que interferem nas dinâmicas sócio-político-linguísticas do país com força suficiente para que se mantenha viva a reflexão acerca da chamada "Lusofonia Leste-Timorense”. 
Pensar na lusofonia talvez não se restrinja a se "pensar na língua" ou em aspectos culturais "comuns" a países que se denominam lusófonos. Pois pensar em uma comunidade lusófona, nesse sentido, não caberia incluir, por exemplo, países como a Guiné Equatorial, que adotou recentemente o português como língua oficial, apesar desta não ser falada por sua população e nem ser incluída como uma das opções de leitura na página oficial do governo na internet. $\mathrm{O}$ que seria então essa lusofonia, a não ser o que o sociólogo português Eduardo Lourenço (1999) observou como parte da identidade portuguesa, como uma saudade do passado? Ou seja, apesar do processo de descolonização já ter ocorrido, a manutenção do império português agora se perpetua no discurso sobre uma suposta herança comum.

Mas, se voltarmos novamente nossos olhares para Timor-Leste, a situação não é diferente. Distante geograficamente do mundo dito lusófono, o país fez a opção política por pertencer a esse espaço, na aposta de que assim se inseriria na modernidade. Se isso está ocorrendo, pelo menos em relação à questão linguística local a população timorense ainda não se beneficia desta suposta modernidade. Pelo contrário, conforme pudemos observar, os principais beneficiários da lusofonia em Timor-Leste são ainda os programas de cooperação luso e brasileiro, que encontraram na meia ilha asiática campo para desenvolverem projetos educacionais e empresariais. A tão defendida autonomia nacional ainda é refém destes programas. Enquanto as práticas linguísticas locais - híbridas, translinguísticas e dinâmicas - e as representações locais de língua não forem consideradas na definição das políticas linguísticas, a sociedade timorense corre o risco de perpetuar profundas desigualdades em nome de um ideal lusófono.

\section{Referências}

ALTHUSSER, L. Ideologia e aparelhos ideológicos do Estado. 3. ed. Lisboa: Presença, 1980.

ANDERSON, B. Comunidades Imaginadas. Reflexões sobre a origem e a difusão do nacionalismo. São Paulo: Companhia das Letras, 2008.

BELO, D. C. Os Antigos Reinos de Timor-Leste. Porto: Porto Editora, 2013.

BEREMBLUM, A. A invenção da palavra oficial. Identidade, língua nacional e escola em tempos de globalização. Belo Horizonte: Autêntica, 2003.

BRESSER-PEREIRA, Luiz Carlos. Nacionalismo no centro e na periferia do capitalismo. Estudos Avançados, v. 22, n. 62, p. 171-192, jan./abr. 2008. 
BOURDIEU, P. A economia das trocas simbólicas. 2. ed. São Paulo: Perspectiva, 1982.

CALVET, J. L. As poli冈ticas lingui冈sticas. Floriano囚polis: Ipol; Sa o Paulo: Para囚bola, 2007.

CANAGARAJAH, S. Reconstructing local knowledge, reconfiguring language studies. In: . (Org.). Reclaiming the local in language policy and practice. New Jersey: Lawrence Erlbaum Associates, 2005. p. 3-24.

DURAND, F. História de Timor-Leste: da pré-história à actualidade. Lisboa: Lidel, 2009. FOUCAULT., M. Microfísica do Poder. 26. ed. São Paulo: Graal, 1997.

GARCIA, O; WEI, L. Translanguaging: Language, Bilingualism and Education. London: Palgrave Macmillian, 2013.

GUSMÃO, X. Discurso proferido no John Hopkins University em 24 de fevereiro de 2011. Disponível em: http://forum-haksesuk.blogspot.com.br/2011/02/adeus-conflito-bem-vindo.html. Acesso em: 03 ago. 2016.

HALL, S. A identidade cultural na pós-modernidade. Rio de Janeiro: DP\&A Editora. 2005. HOBSBAWN, E.; RANGER, T. (Org.). A Invenção das Tradições. 10. ed. São Paulo: Paz e Terra, 2015.

LANDRY, R.; BOURHIS, R.Y. Linguistic Landscape and Ethnolinguistic Vitality: An empirical study. Journal of Language and Social Psychology, v. 16, n. 1, p. 23-49, 1997.

LOPES DA SILVA, F.; RAJAGOPALAN, K. (Org.). A linguística que nos faz falhar: investigação crítica. São Paulo: Parábola Editorial, 2004.

LOURENÇO, E. A Nau de Ícaro. Lisboa: Gradiva, 1999.

MACALISTER, J. Language policies, language planning and linguistic landscapes in Timor-Leste. In: DASGUPTA, P; MARK, F (eds). Language Problems \& Language Planning. [S.1.]: John Benjamins Publishing Company, 2013. p. 25-45.

MAKONI. S.; PENNYCOOK, A. (Orgs.). Disinventing and Reconstituting Languages. Clevedon: Multilingual Matters, 2007.

.; SEVERO, C. Políticas Linguísticas Brasil-África. Florianópolis: Insular, 2015.

MARGARIDO, A. A lusofonia e os lusófonos: novos mitos portugueses. Lisboa: Edições Universitárias Lusófonas, 2000.

MARIANI, B. Colonização Linguística. Campinas: Pontes, 2004.

PENNYCOOK, A. Critical Applied Linguistics: A Critical Introduction. Mahwah: Lawrence Erlbaum, 2001.

. The Myth of English as an Internacional Language. In: MAKONI, Sinfree; PENNYCOOK, A. (Org.). Disinventing and Reconstituting Languages. Clevedon: Multilingual Matters, 2007. p. 90-115. 
. Language as Local Practice. London: Routledge, 2010.

QUIJANO, A. Colonialidade do poder, Eurocentrismo e América Latina. In: LANDER, E. (Org.). A colonialidade do saber: eurocentrismo e ciências sociais. Perspectivas latinoamericanas. Buenos Aires: CLACSO, 2005. p. 117-142.

RAJAGOPALAN, K. Política Linguística: Do que e que se trata, afinal? In: NICOLAIDES, C.; SILVA, K. A. da; TILIO, R.; ROCHA, C. H. (Org.). Politica e Políticas Linguísticas. Campinas: Pontes Editores, 2013. p. 19-42.

RAJAGOPALAN, K. Por uma linguística crítica: linguagem, identidade e a questão ética. São Paulo: Parábola Editorial, 2003.

RIBEIRO DA SILVA, E. A Pesquisa em Política Linguística. Histórico, Desenvolvimento e Pressupostos Epistemológicos. Trabalhos em Linguística Aplicada, Campinas, v. 52, n. 2, p. 289-320, jul./dez. 2013.

SEVERO, C.; SITOE, B. \& PEDRO, J. Estão as Línguas Nacionais em Perigo? Lisboa: Escolar Editora, 2014.

THOMAZ, L. F. Babel Loro Sa'e. O Problema Linguístico de Timor-Leste. Lisboa: Instituto Camões, 2002.

TIMOR-LESTE. Constituição da República Democrática de Timor-Leste. Díli, Assembleia Constituinte, 2002. Disponível em: http://timor.no.sapo.pt/constibase.html.

Data de submissão: 25/07/2016

Data de aceite: $28 / 07 / 2016$ 